\title{
A statistical definition of the Antarctic marginal ice zone
}

\author{
Marcello Vichi ${ }^{1,2}$ \\ ${ }^{1}$ Department of Oceanography, University of Cape Town, 7701, Rondebosch, South Africa \\ ${ }^{2}$ Marine and Antarctic Research centre for Innovation and Sustainability (MARIS), University of Cape Town, 7701, \\ Rondebosch, South Africa
}

Correspondence: Marcello Vichi (marcello.vichi@uct.ac.za)

\begin{abstract}
The marginal ice zone (MIZ) is a transitional region between the open ocean and pack ice. This region is circumpolar in the Antarctic, with different sea ice types depending on the season and the sector of the Southern Ocean. The MIZ extent have traditionally been inferred from satellite-derived sea-ice concentration (SIC, one of the essential climate variables), using the $15-80 \%$ range as indicative of sea ice with MIZ characteristics. This proxy has been proven effective in the Arctic, where there is a good correspondence between sea-ice type and sea-ice cover. It is less reliable in the Southern Ocean, where seaice type is less linked to the concentration value, since wave penetration and free drift conditions have been reported with $100 \%$ cover. I propose an alternative definition of the MIZ that is based on statistical properties of the SIC and its spatial and temporal variability. The indicator is derived from the standard deviation of daily SIC anomalies, which is often employed in the climate sciences. The use of a monthly climatological mean as the baseline allows to capture changes due to both the seasonal advancement/retreat and the local weather-driven variability typical of less consolidated sea-ice conditions. This method has been tested on the available climate data records to derive maps of the MIZ distribution over the year. It reconciles the discordant seasonal extent estimates using the SIC threshold, which is now independent of the used algorithm. This indicator also allows to derive the climatological probability of exceeding a certain threshold of SIC variability, which can be used for ship navigation, design of observational networks and for testing the skills of sea-ice models in forecasting or climate mode.
\end{abstract}

\section{Introduction}

The Southern Ocean holds the largest circumpolar marginal ice zone (MIZ) in the world ocean (Weeks, 2010, p. 408), while in the Arctic MIZ features are mostly confined to the Bering Sea and the Greenland and Norwegian Seas (Wadhams, 2000). The MIZ is a transitional region, and as such, it is often defined by contrasting consolidated pack ice and open ocean conditions. This implies the identification of two boundaries, one at the ice-ocean margin and one within the pack ice. The ocean edge and the MIZ extent are inextricably linked, since it is difficult to find sharp separations between these two realms. Hence, the definition of the MIZ in the literature depends on the properties that are of interest in each study and often on the polar hemisphere considered. Following on from Arctic studies, the boundaries are derived from contour lines of sea-ice concentration (SIC), the fraction of ice-covered water obtained through passive microwaves sensors onboard satellites (Comiso and Zwally, 1984; Meier and Stroeve, 2008/ed; Strong and Rigor, 2013; Stroeve et al., 2016). Operationally, the MIZ is defined as that region of the sea ice where SIC is comprised between 15 and 80\%, and the MIZ extent depends on how the distance between these 
https://doi.org/10.5194/tc-2021-307

Preprint. Discussion started: 27 October 2021

(c) Author(s) 2021. CC BY 4.0 License.

\section{(c) $\underset{\mathrm{BY}}{\mathrm{BV}}$}

contours are computed (Strong et al., 2017). This definition is tightly linked to the SIC retrieval from satellites, since the limit of $15 \%$ is considered to be a viable rule-of-thumb to overcome the uncertainties in the methodology (Comiso and Zwally, 1984). Within this range, sea ice is assumed to be in open pack conditions, with higher chances of drifting ice and the penetration of gravity waves due to the floes being smaller than the wave length (Squire, 2020). As an alternative definition, it has been proposed to estimate the MIZ extent based on the region where the wave field would be responsible for setting the sea-ice thickness (Williams et al., 2013; Sutherland and Dumont, 2018).

The concentration-based definition of the MIZ is the one most often used to estimate temporal trends in the MIZ extent at both poles (Strong and Rigor, 2013; Strong, 2012; Stroeve et al., 2016; Rolph et al., 2020), with contrasting results that may be partly attributed to methodological issues (Strong et al., 2017). Stroeve et al. (2016) found large differences in estimating the seasonal cycle of the Antarctic MIZ extent using different algorithms. Over a climatological seasonal cycle, the Bootstrap method returned a higher percentage of consolidated pack ice than the NASA Team algorithm, and this leads to differences in the trend analyses. However, a most pressing question is not whether the MIZ has been increasing or decreasing in the Antarctic and how different it is from the Arctic, but rather if the Antarctic MIZ features can be properly captured using the threshold-based concentration criteria that is at the base of the MIZ operational definition. This definition has been applied directly to Antarctic sea ice despite the remarkable differences in sea-ice formation processes (e.g. Weeks and Ackley, 1986; Petrich and Eicken, 2017; Maksym, 2019). Almost all the proposed parameterizations of energy, momentum and gas exchange through sea ice are linearly dependent on the area cover fraction (Steele et al., 1989; Martinson and Wamser, 1990; Worby and Allison, 1991; Andreas et al., 1993; Martinson and Iannuzzi, 1998; Bigdeli et al., 2018; Gupta et al., 2020). They have also been implemented assuming constant sea-ice features, with only recent formulations including ice deformation (see Castellani et al., 2018, and references therein). However, this only includes the role of thickness and ice topography, which is more likely to be determinant in the Arctic, due to the broader thickness distribution (Haas, 2017). In predominantly seasonal sea ice, with continuous transition between new and young ice and the dominance of frazil ice (Matsumura and Ohshima, 2015; Haumann et al., 2020; Paul et al., 2021), the exchange across the interface may be less dependent on the degree of coverage, and rather be affected by the composite of the sea-ice textures. Small daily changes in ice concentration features and surface deformation have been observed far into the pack ice region (Kohout et al., 2014; Vichi et al., 2019), which could indicate changes in the sea-ice properties, structure and (thermo)dynamic behaviour.

Every latitude of the Southern Ocean, apart form the few regions of multi-year ice, can be classified as seasonal sea ice zone and will have a period of time showing MIZ characteristics. In most general terms, the MIZ can be depicted as a band of young or fractured ice (and their combination) that is continuously affected by air-sea interactions, in the form of heat exchanges, wind and current drag, and wave action. In the Antarctic, the MIZ is a characteristic of the advancing edge, since during this phase sea ice progresses northwards and expands zonally due to the increase in ocean surface towards the equator. This leads to divergence and lowers the chances of rafting and ridging, which are still considered the main thickening mechanisms in the Southern Ocean ((Worby et al., 1996)). The use of a concentration-based MIZ definition is indeed operationally viable at the monthly scale in the Antarctic. Assuming that the sea-ice edge is traversing a region of open ocean in one month with constant speed, this area is likely to be classified as MIZ, since it will have an expected monthly SIC equal to $50 \%$. This is more unlikely 
to happen during the retreat phase, due to the asymmetric seasonality of Antarctic sea ice (Eayrs et al., 2019), and because of sudden changes in ice concentration that may occur due to the substantial interannual variability during melting (Turner et al., 2017; Parkinson, 2019). Concentration-base ice-edge identification are thus more reliable during wintertime (Worby and Comiso, 2004). This definition is therefore indicative more of the seasonal ice zone and the transition between new and young ice, rather than a measure of the MIZ, in which ocean and atmospheric processes are determinant in shaping the dynamics of sea ice at multiple time scales.

In this work I reassess the assumption that absolute values of sea-ice concentration contain information on the sea-ice type in the Antarctic, in stark contrast with the Arctic, where the correspondence between ice cover and ice type allows to discriminate first year (seasonal) ice from multi-year ice, with the subsequent emergence of categories based on thickness and ice-age. This is less relevant in the Antarctic, where the majority of sea ice is thin and seasonal. Antarctic sea ice cannot thus be decomposed in further categories, unless through the use of high-resolution images. Given that the only available data at the planetary scale are passive microwave data of brightness temperature, there is merit in investigating whether smaller changes in pixel concentration from remote sensing hold some consistent measure of change in ice character. The interest here is not whether the retrieval of brightness temperature is measuring the actual concentration of ice-free versus ice-covered ocean, but rather if the relative change in this proxy is representative of a physical variation in sea ice state. This is the rationale of the method proposed here. In the following, I will demonstrate how the use of an indicator based on the sea-ice concentration standard deviation of daily anomalies computed over the monthly time scales allows to reconcile the disparity observed in the seasonality of the MIZ extent in the Antarctic. The method can also be used to construct climatological maps of SIC variability beyond the concept of the MIZ, hence assisting with navigation, design of observational experiments and assessment of model outputs.

\section{Methodology}

\subsection{Remote sensing data}

The analysis was carried out using SIC data from the sea ice Climate Data Records (CDR) from NOAA/NSIDC (Peng et al., 2013; Meier et al., 2017) and from the EUMETSAT OSI SAF (OSI-450) product (Lavergne et al., 2019). The former contains two main data sets: the official CDR from July 1987 to December 2019, which follows all the CDR standards for traceability and reproducibility, and the Goddard merged product (hereinafter NOAA/NSIDC GM), which includes additional manual corrections and spatial/temporal interpolations to fill data gaps (extending the period back to January 1979). These products are very similar in terms of the longer-term properties (Peng et al., 2013) but differ in the individual daily maps. The OSI450 product is a gap-less, level 4 product, similar to the Goddard merged product. It extends from January 1979 through to December 2015. The data processing introduced an open-water filter aimed at removing weather-induced false ice over open water, which unfortunately may remove some true low-concentration ice in the MIZ (Lavergne et al., 2019). For the purpose of this analysis, which focuses on daily variability, the NOAA/NSIDC CDR is preferable since it introduces less smoothing and 
aliasing, as well as it ensures continuity with future releases of the data set. The results will be discussed against the other data sets and the corresponding figures for the NOAA/NSIDC GM and OSI-450 CDR are available in the supplementary material.

\subsection{Statistical analysis}

The methodology treats the variability of remote-sensed SIC as if it were a perturbation around an expected value. In the following, SIC is expressed as the fraction between 0 and 1; this value is assumed to be an objective measure of sea-ice state rather than an actual indicator of ocean coverage. Regions of closed pack ice, or of ice-free ocean outside the seasonal ice zone are more likely to experience small variations around a long-term mean value of the SIC (close to 1 in the former case and to 0 in the latter). Persistent conditions of multi-year ice and permanently ice-free ocean will have less noise, hence a negligible dispersion around the climatological mean. The standard deviation of the daily SIC anomaly with respect to a chosen reference value can thus be used to measure the degree of variance in sea-ice conditions experienced by a certain pixel over a month.

The daily SIC anomaly for each pixel is computed by subtracting the daily SIC from the monthly climatology $\bar{C}^{n}$ :

$a_{i}^{m}=C_{i}^{m}-\bar{C}^{n}$

where the index $i$ runs over the number of days in month $m$ and $n=1, \ldots, 12$ indicates the month of the year. The index $m$ runs over the total number of months in the time series (e.g. 396 for NOAA/NSIDC CDR). The reason for choosing the monthly climatology as the reference value is crucial for the analysis and further explained below. Since the variable SIC is constrained between 0 and 1 , so is the anomaly. The standard deviation of the daily anomaly is then computed for each month, to measure the spread around the climatological SIC monthly mean as follows:

$110 \sigma_{S I A}^{m}=\sqrt{\frac{1}{N} \sum_{i=1}^{N}\left(a_{i}^{m}\right)^{2}}$,

where $N$ is the total number of days in the month. The standard deviation is effectively a sum of squares, since the mean of the anomalies is null. The climatological monthly standard deviation of the anomalies $\left(\bar{\sigma}_{S I A}^{n}\right)$ has also been computed by pooling together all the daily anomalies from the same month in different years

$\bar{\sigma}_{S I A}^{n}=\sqrt{\frac{1}{N} \sum_{j=1}^{N \times Y}\left(a_{j}^{n}\right)^{2}}$,

with $Y$ is the number of years, and the index $j$ runs over the number of days of the Januaries, Februaries, etc. The variable $\sigma_{S I A}^{m}$, hereinafter referred to as "the indicator" $\sigma_{S I A}$ with the index $m$ dropped, describes a left bounded distribution, where the value 0 indicates lack of SIC variability over the month and the maximum expected value is 0.5 . The exclusion of the zeroes represents an unbiased distribution of SIC variability.

This analysis does not deliberately discriminate between a point that is experiencing a seasonal transition of the MIZ band during sea-ice advance or a persistence of short-term variable SIC conditions more typically ascribed to the ice edge. This is the main reason for using the daily anomaly against the monthly climatology instead of the daily climatology (based on daily 
https://doi.org/10.5194/tc-2021-307

Preprint. Discussion started: 27 October 2021

(c) Author(s) 2021. CC BY 4.0 License.

(c) (1)

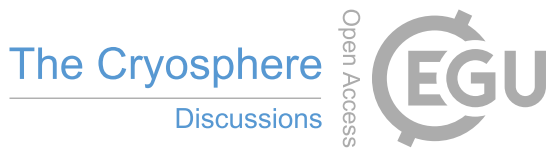

values or daily running means over a weekly to monthly time window). The use of a filtered background climatology with a window shorter than a month would include the smooth daily transition during the advance and retreat phase. It does retain some measure of variability but reduces the variance of the signal due to the meridional advancement, which is a fundamental characteristics of the MIZ. Since the anomaly is computed roughly over the same number of days for each pixel (excluding the random missing data), it is more likely that a rapid transition between new, young and first-year ice would result in an overall lower value of the monthly indicator, nevertheless recording the information that this region of the ocean has been partly interested by changes in SIC.

The indicator is used to estimate the chances of encountering variable MIZ conditions at each pixel on a monthly climatological time scale. The probability of an ocean region being affected by MIZ conditions during a given month has been computed using the empirical exceedance (which is equivalent to 1 - CDF, the cumulative density function, when the function is known):

$E P=1-\frac{r}{N}$

where $r$ is the rank of the sorted series of $\sigma_{S I A}^{m}$ values. Given a certain threshold of the indicator that is known to correspond to MIZ conditions, this function gives an estimate of the probability to exceed that value based on the records. 


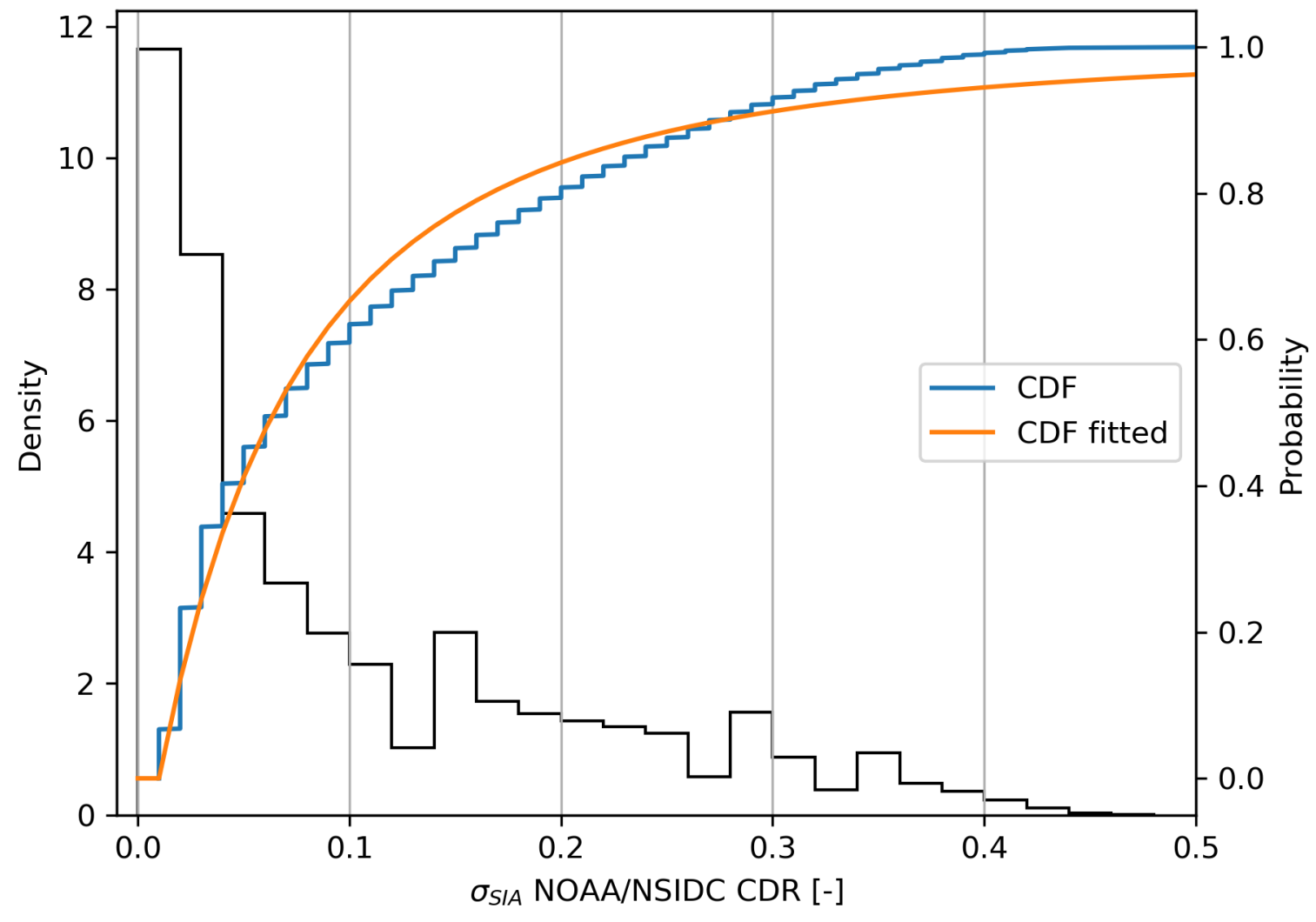

Figure 1. Empirical probability (black line) and cumulative (blue line) density functions of the $\sigma_{S I A}$ indicator from the NOAA/NSIDC CDR data set. The orange curve is the fitted Pareto distribution. 

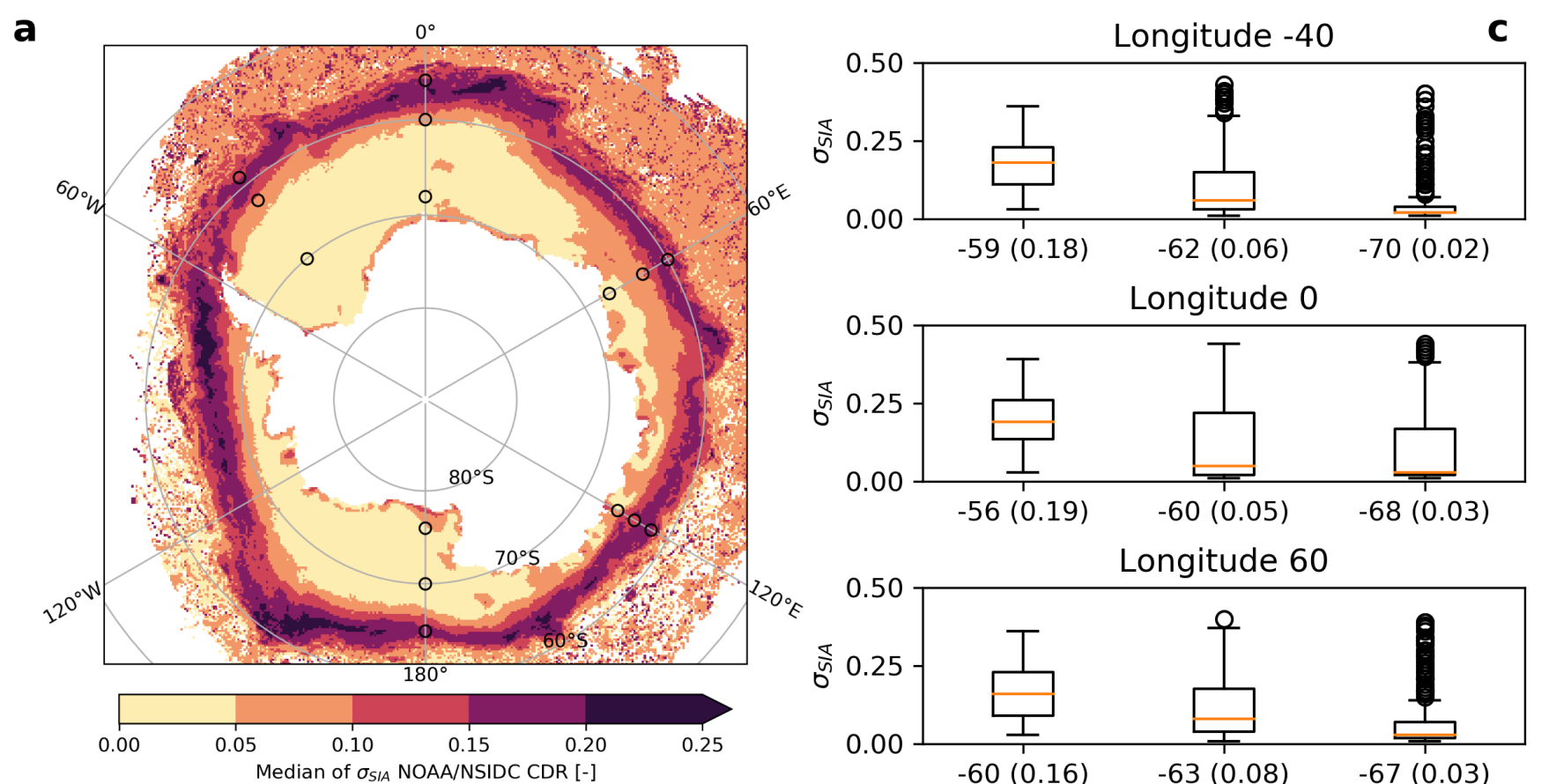

b
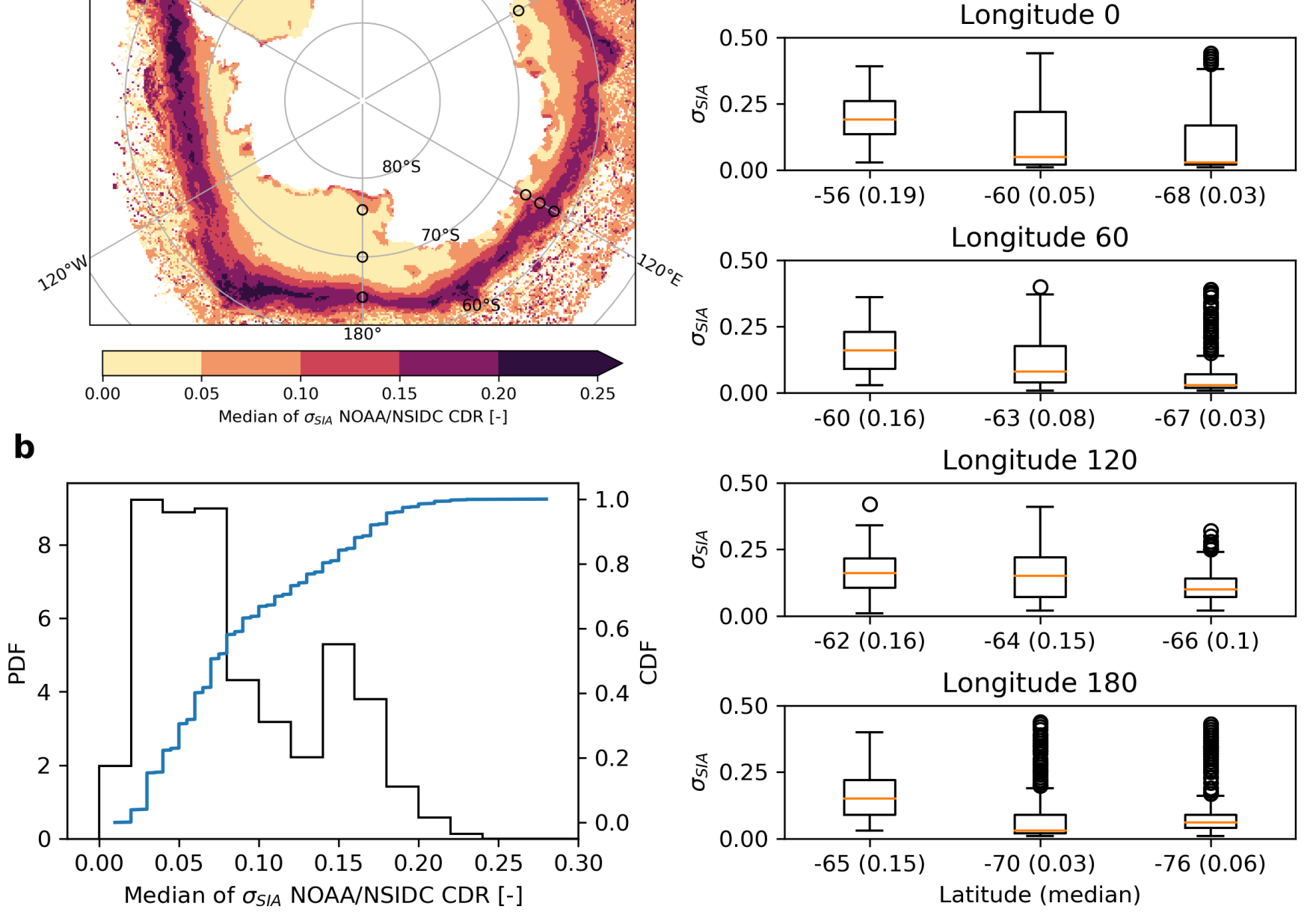

Figure 2. Overview of the variability indicator highlighting the MIZ extent (NOAA/NSIDC CDR, 1987-2019). (a) Median of the monthly standard deviation of sea-ice concentration daily anomaly $\left(\sigma_{S I A}\right)$, plotted on a stereographic projection. The pixels with SIC $=0$ have been excluded from the analysis of the distribution. The circles indicate the locations shown in panel c. (b) Empirical probability and cumulative density functions of the median values from the map shown in panel a (PDF: black line and CDF: blue line). (c) Box-and-whisker plots of the $\sigma_{S I A}$ distribution extracted at the locations shown in panel a. The three subjective latitudes correspond to different values of the median along each selected longitude (orange line, the value is shown in brackets besides the latitude). The sections are roughly located in the traditional sectors of the Southern Ocean. The Amundsen-Bellingshausen Sea (not shown) is similar to longitude $120^{\circ} \mathrm{E}$. 


\section{Results}

\subsection{An indicator of climatological and inter-annual variability for the MIZ}

The empirical distribution of $\sigma_{S I A}$ follows a Pareto distribution (Fig. 1). The cumulative density function is a power law, which can be fitted very well with the Pareto function (p-value of the Kolmogorov-Smirnov test virtually zero; the test had to be run on sub-samples for computational reasons). The empirical function shows a change in curvature for values above 0.1 , which could be indicative of the superposition of two distributions. The sample contains more than 8 million values, which would unlikely explain the discontinuity between 0.1 and 0.2 as an under-sampling issue.

Since the interest is in identifying the typical conditions differentiating the MIZ from more consolidated and less variable sea ice concentration, the median of the indicator computed for each pixel is a useful descriptor of the most common spatial features (Fig. 2a). In a Pareto distribution, the median is biased towards the lower values, hence it is a conservative estimator. Higher values of the $\sigma_{S I A}$ median are indicative of large departures from the long-term mean conditions (when sea ice is present in the region). These highly variable regions are found in the outer part of the sea ice as expected. They are distributed zonally in a rather homogeneous way, with a few peaks in the Bellingshausen, Eastern Weddell Sea $\left(13^{\circ} \mathrm{E}\right)$ and Ross Sea $\left(150^{\circ} \mathrm{W}\right)$ regions, located close to areas of interruptions of the zonal belt. Another area of high median is associated to coastal polynyas. These are known regions, in which the SIC is recognised to be more variable and usually less consolidated. A greater halo of variability is observed in the Atlantic sector, extending to about $55^{\circ} \mathrm{S}$. This halo is removed when the analysis is run on the higher level products such as the NOAA/NSIDC GM and OSIS-450, which are gap-less and/or filtered (Fig. S1 and S2 in the supplementary material).

The median distribution shown in Fig. $2 \mathrm{~b}$ confirms the presence of different processes underlying the variability in Antarctic sea ice, which was hinted at when analysing the overall distribution in Fig. 1). The $\sigma_{S I A}$ median distribution is more normal and bimodal, also constrained below 0.3 ( 0.2 is the 99th percentile). The first peak is larger and centred around 0.05 and the second one is above 0.15 , with a trough between 0.1 and 0.15 . The change of slope in the empirical CDF is more evident here and corresponds to the range of values where the two distributions intersect. By combining the spatial map with the distribution of the median, it appears evident that values between 0.1 and 0.15 indicate mixed regions were consolidated pack ice may show concentration changes akin to the features observed at the ice margin, and values above 0.15 can be clearly identified as having MIZ-like features. In the following, I will use a threshold of 0.1 and will discuss the implication of this choice in the discussion. Note that this analysis does not differentiate regions of high variation based on the distance from the continent, as for instance done in (Stroeve et al., 2016) with the SIC threshold criteria. MIZ-like conditions can also be found in the interior of the sea ice, as it will be shown in the next section. The same analysis done on the NOAA/NSIDC GM and OSI-450 data sets shows similar features (Fig. S1 and S2 in the supplementary material), although the heavier filtering and gap-filling used in OSI-450 introduces a smoothing in the distribution of the median that flattens the second peak and removes much of the variability in the MIZ (Fig. S2, bottom panel).

This average perspective may however mask the possibility of detecting extreme changes in regions that are typically characterised by one type of ice. Fig. $2 c$ shows the complete distributions from selected points. The median and the interquartile 
ranges decrease moving southward along sections marking the standard Antarctic sectors, but in general the outliers become more evident. Regions of intermediate ice variability, as for instance the Weddell Sea at $60^{\circ} \mathrm{S}$, may be largely asymmetric and hence uncertain, as indicated by the long tail of the empirical distribution. The median variability is low, but there are high chances of the SIC being different from year to year in a given month. In Eastern Antarctica $\left(120^{\circ} \mathrm{E}\right)$, where the sea-ice extent is narrower, it is hard to distinguish the presence of more persistent pack ice conditions. The median is high, close to 0.1 and above, with more symmetric distributions. The Ross Sea, is more similar to the Western Weddell Sea, with sporadic extreme values indicating departures from the typical ice conditions found in the internal pack ice regions. However, this sector has a narrower MIZ in the outer region and the internal pack ice is less variable than the ice closer to the continent, which is instead affected by the variations due to the coastal polynyas. It should also be noted that this analysis evidences the persistent presence of large variability corresponding the Maud Rise "open-ocean" polynya, as well as the region corresponding to the Belleny Islands in the Ross Sea.

This method is designed to highlight regions where ice features based on SIC estimates are more variable between the years. The NOAA/NSIDC CDR climatological $\bar{\sigma}_{S I A}^{n}$ is shown in Fig. 3 as a reference example of the intensity of the SIC variability in the Southern Ocean. The NOAA/NSIDC GM and OSI-450 are substantially equivalent but with less noise associated to values lower than 0.1 in the open ocean region (see Fig. S3 and S4 in the supplementary material). The OSI-450 product also leads to slightly smaller values of the $\sigma_{S I A}$ climatology at the ice edge because of the use of a stronger open-ocean filter. The extent of the regions presenting MIZ features increases from November to December in a diffused fashion. Later in the season, they are confined within a band that progresses northward and shrinks at the boundary with the ocean. The higher values and the largest meridional spread are found in April and May in the Weddell and Ross Seas. In June and July, the large expanse of the Eastern Weddell Sea between $15^{\circ} \mathrm{W}$ and $40^{\circ} \mathrm{E}$ corresponding to the Atlantic bulge of the sea-ice edge is characterised by large inter-annual SIC variability that extends towards the continent. The value of the indicator can also be appreciated by looking at how it captures the variability corresponding to the Maud Rise polynya. The impact on SIC variability in this area is visible from September throughout November, with the latter characterised by a climatological value above 0.2 over a large expanse of the sea-ice covered region. In November, this region denotes a decrease of the indicator, because the polynya is usually fully developed and the open ocean traits prevail.

The climatological maps are useful to highlight the seasonal features of the MIZ, which will be further analysed in the next section. The indicator is also of value in detecting inter-annual variability in given months. For instance, Fig. 4 shows how anomalous November 2016 was with respect to the previous years. The whole Atlantic sector was characterised by extended MIZ conditions not only in the region of the Maud Rise, which persisted until 2019. Similar conditions were previously observed in 2009-10, which was also another period of negative anomalies of sea-ice extent recorded in the Weddell Sea and Indian Ocean regions (Parkinson, 2019, , see her Fig. 3 and 4). 

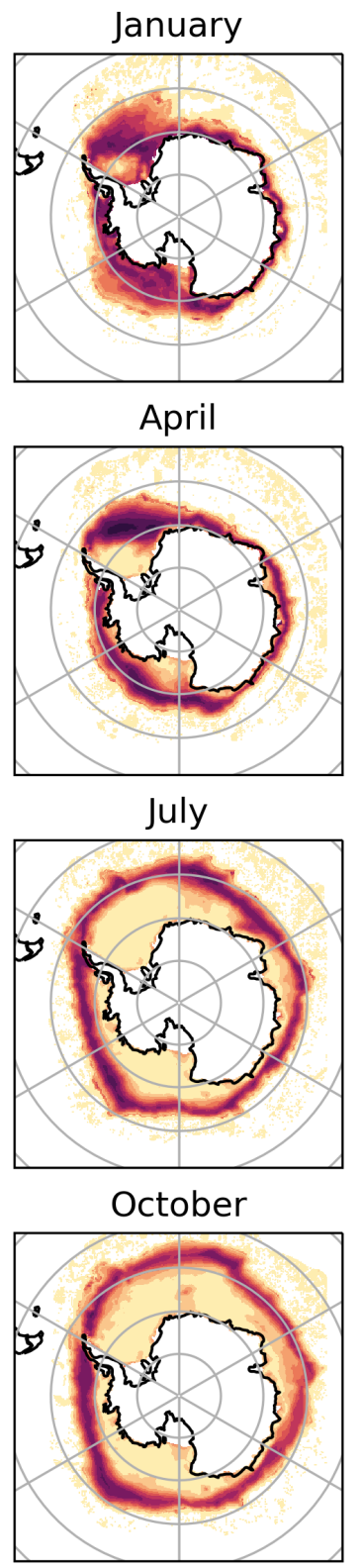
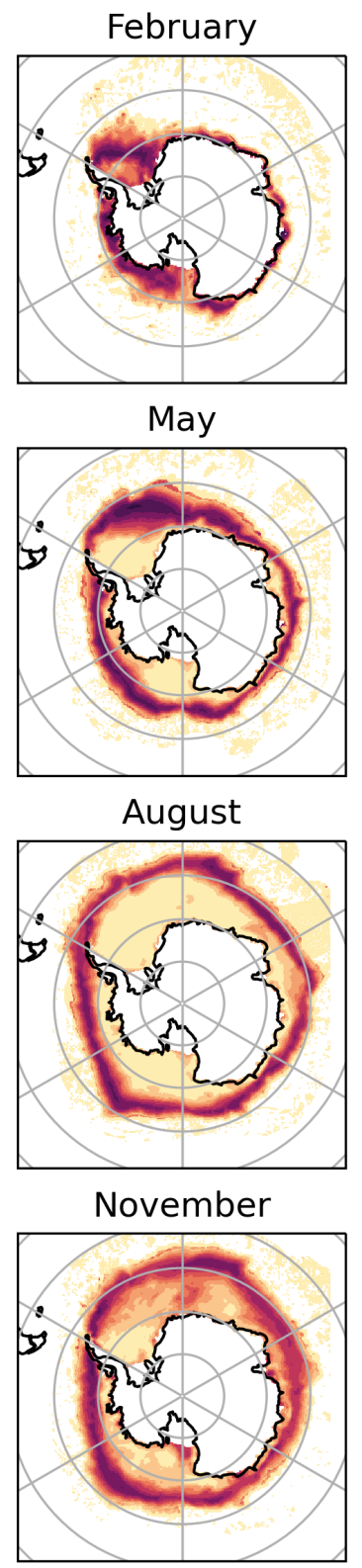
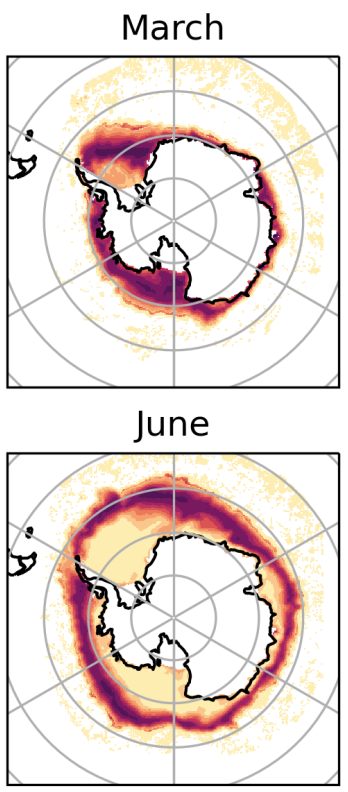

September

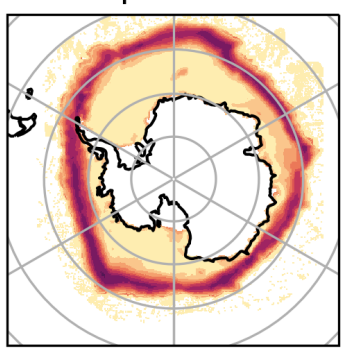

December

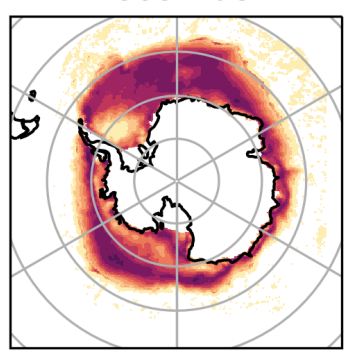

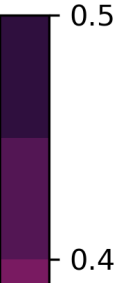

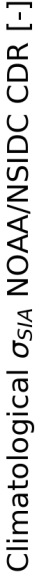

0.1

0.0

Figure 3. Climatological values of the indicator $\left(\bar{\sigma}_{S I A}^{n}\right)$, computed as the standard deviation of the daily anomalies for each month in the whole time series (see eq. 3 ). 

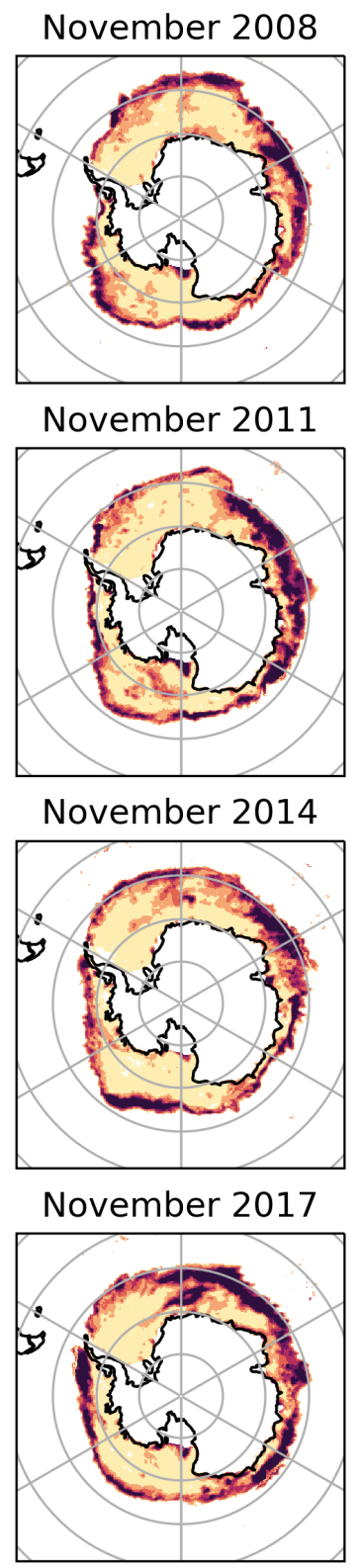
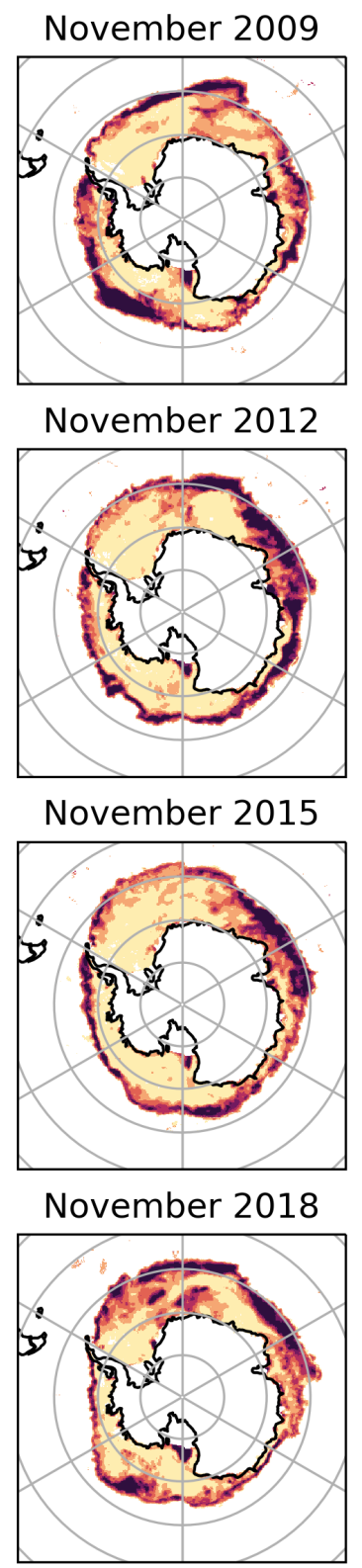

November 2010

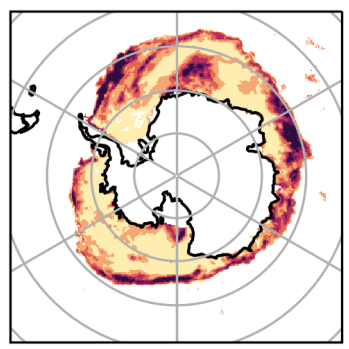

November 2013
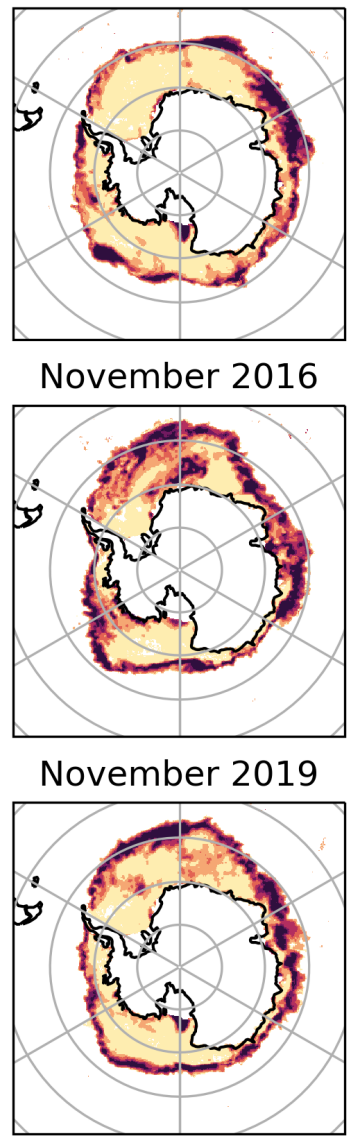

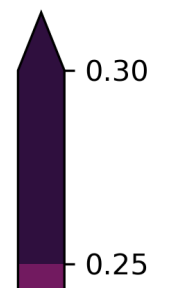

$-0.205$

ำ

产

$0.15 \frac{2}{8}$ 离

0.10

0.05

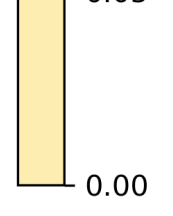

Figure 4. November maps of the $\sigma_{S I A}$ indicator from the NOAA/NSIDC CDR for the years 2008-2019. Note the scale change with respect to Fig. 3. 

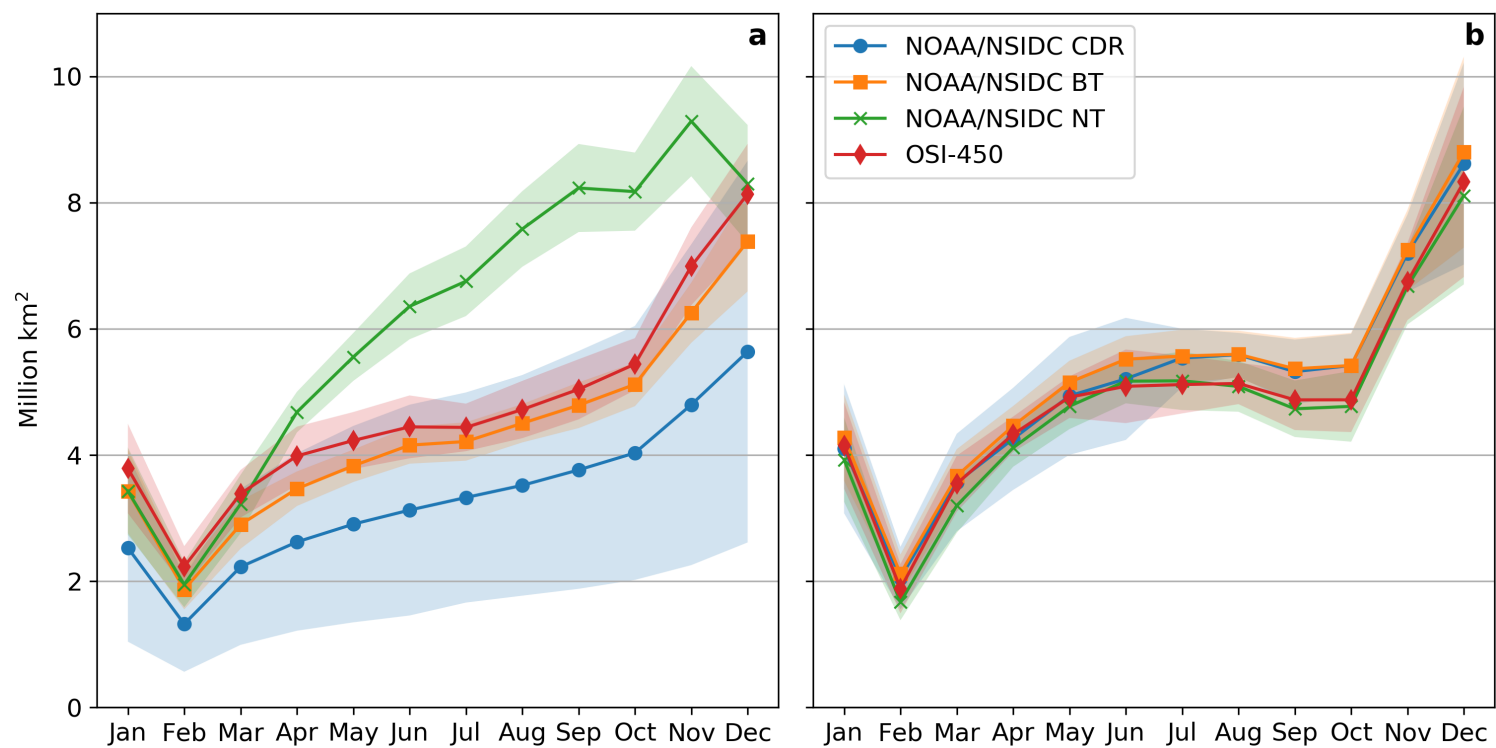

Figure 5. Seasonal cycle of the MIZ extent estimated from the a) SIC criterion $(0.15 \leq \mathrm{SIC}<0.80)$ and b) the $\sigma_{S I A}$ indicator $\left(\sigma_{S I A}^{m}>0.1\right)$. The results are shown for all the products described in Sec. 2.1. The NOAA/NSIDC GM curve is not shown because very similar to the BT data set. 
https://doi.org/10.5194/tc-2021-307

Preprint. Discussion started: 27 October 2021

(c) Author(s) 2021. CC BY 4.0 License.

\section{(c) (i)}

\subsection{Patterns of seasonal variability}

The above analysis remarks that, due to the intrinsic seasonal nature of Antarctic sea ice, there are wide regions where SIC shows high inter-annual variability in any month of the year, which is not captured by analysing the mean concentration. To strengthen this concept, the seasonal cycle of the circumpolar MIZ 'classical' extent was computed from the monthly indicator $\sigma_{S I A}^{m}$ for every year and then averaged. This measure is comparable to using the mean monthly SIC comprised between 0.15 and 0.80 to compute the extent. Following from the results shown in Sec. 3.1, any pixel with a value of the indicator larger than 0.1 was assumed to be characterised by MIZ processes and included in the areal count. Fig. 5 shows the comparison between the MIZ extent computed using the traditional SIC criterion and the one proposed here, for all the products described in Sec. 2.1. As previously shown by (Stroeve et al., 2016), the MIZ area based on the SIC threshold is largely affected by the chosen algorithm, which diminishes the reliability of these estimates. In their analysis, the NT algorithm had a higher MIZ area than BT and a larger proportion of inner open-water ice and coastal polynyas, which are included in this MIZ SIC-based criterion and hence the absolute value shown here is higher than the one presented in Stroeve et al. (2016, their Fig. 5). The MIZ extent computed through the indicator is instead independent of the algorithm choice or product, because the relative variability is equally captured. Using a threshold of 0.15 , corresponding to the median peak in Fig. $2 \mathrm{~b}$ led to a seasonal extent that is lower than using the SIC method (Fig. S5 in supplementary material), further indicating that the chosen threshold is more adequate.

This indicator quantifies the intensity, as opposed to the SIC criterion, which simply returns a binary mask. A climatological MIZ mask can still be obtained by considering the pixels that are climatologically more likely to present MIZ features (values of the climatological indicator $\bar{\sigma}_{S I A}^{n}>0.1$, Fig. 6 ). Here we observe that the two criteria are more similar in the winter to early spring months from July to October. However, the MIZ mask based on the indicator is generally wider and more extended both onto the open ocean and into the pack ice. This is more evident in the Eastern Weddell Sea from $0-50^{\circ} \mathrm{E}$, and also in the Ross Sea between $120-160^{\circ} \mathrm{W}$. This difference increases from October to June, with a peak in November. This is indeed the month that has shown the largest variability in the record (Turner et al., 2017), as previously highlighted in Fig. 4.

There is a fundamental computational difference between the climatological averaging of the monthly extents shown in Fig. 5b, in which a monthly mask is multiplied by the pixel area then integrated and averaged, and the mask based on the climatological monthly standard deviation of the daily anomalies $\bar{\sigma}_{S I A}^{n}$. This is because the average of the standard deviations computed from sub-samples of a population is different from the standard deviation of the whole population. Note that this difference also applies to the computation of the extent using the SIC criterion. Hence, the climatological MIZ extent shown in Fig. 5 is an underestimation of the sea-ice area that may statistically present MIZ characteristics. This is graphically shown in Fig. 7, where the climatological sea-ice extent (SIE) is computed from the SIC criterion and $\bar{\sigma}_{S I A}^{n}$ indicator (the area of the yellow-shaded region in Fig. 6) using the NOAA/NSIDC CDR. The MIZ SIE obtained when using the climatological SIC criterion (the line with the crosses) is also higher than the one shown in Fig. 5a (compare with the blue line obtained from the same product). It should not be surprising that the MIZ extent presented in this work exceeds the total SIE. This is because this method detects pixels that are statistically more likely to be interested by inter-annual changes in SIC, as it will be explained further in the next section. 
https://doi.org/10.5194/tc-2021-307

Preprint. Discussion started: 27 October 2021

(c) Author(s) 2021. CC BY 4.0 License.

\section{(c) (1)}

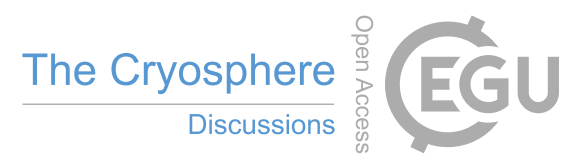

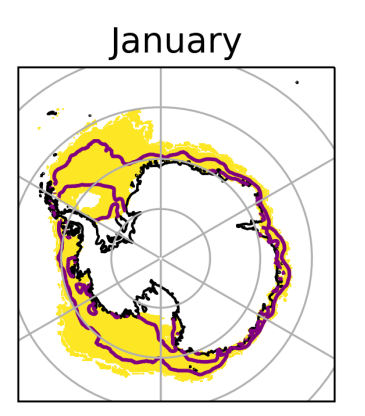
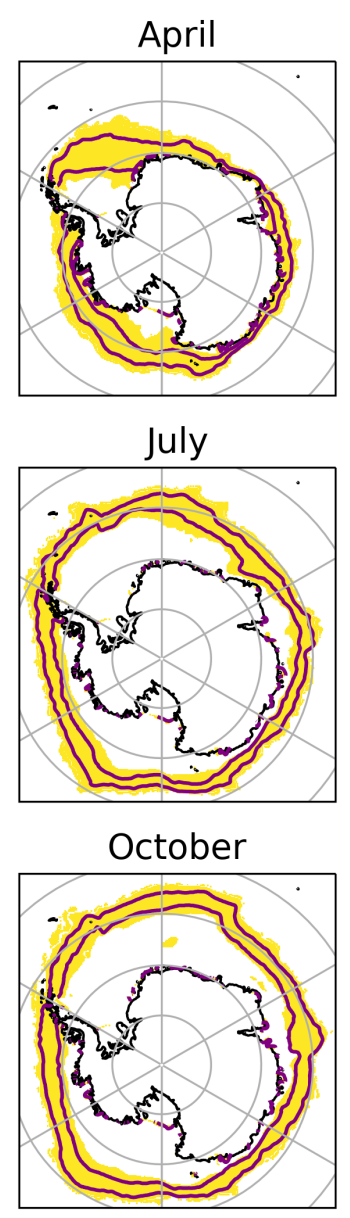
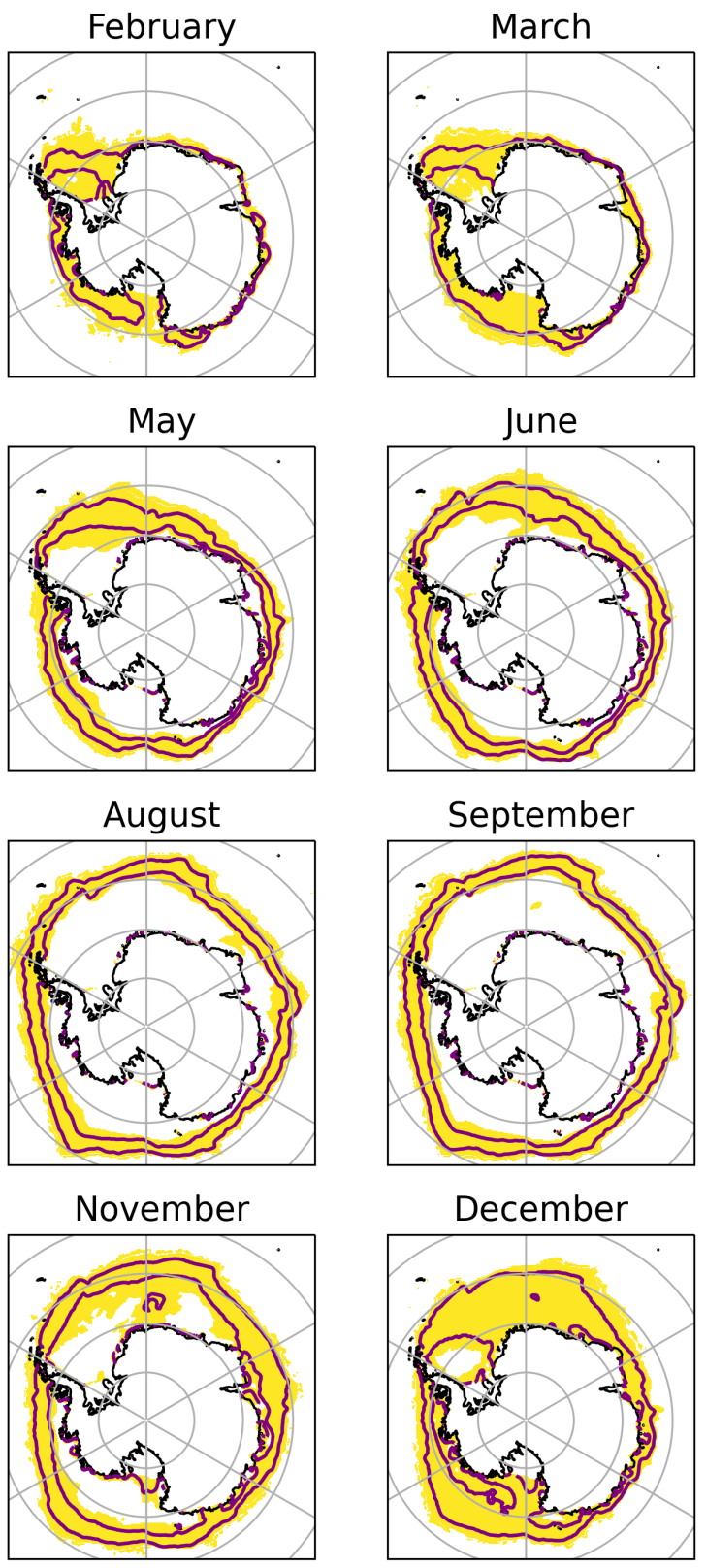

Figure 6. Climatological monthly mask of the MIZ obtained from the indicator. The purple line indicates the MIZ extent computed using the SIC criterion. 


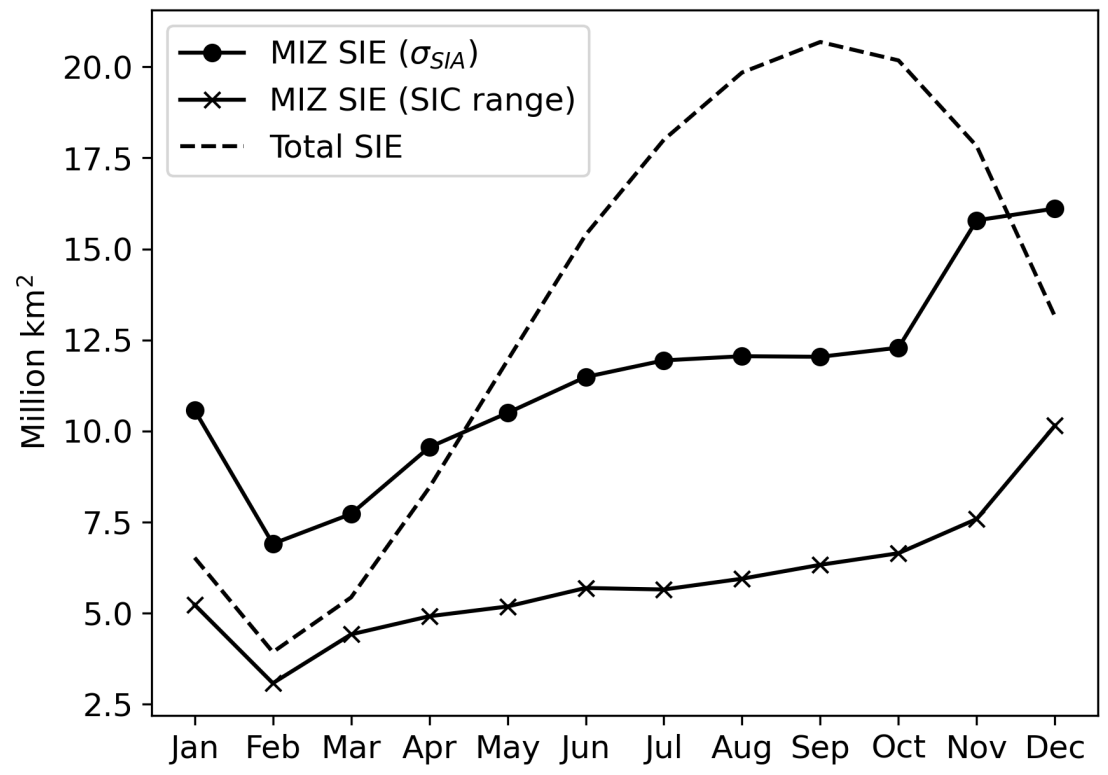

Figure 7. Estimated climatological extent of the MIZ and total sea-ice extent computed from the monthly climatologies of NOAA/NSIDC CRD. The filled-circle line is obtained from the $\bar{\sigma}_{S I A}^{n}$ climatological indicator of SIC variability, using the threshold 0.1 , which also includes the coastal regions. 


\subsection{Exceedance probability of encountering MIZ conditions}

The previous analysis revealed that MIZ-like features in Antarctic sea ice are not necessarily confined to the outer edge or to coastal polynyas, but they can also extend to the interior of the pack ice. It is therefore of interest to quantify the likelihood of encountering MIZ conditions in a selected month, given the consideration that the SIC climatological average is an inadequate descriptor of sea-ice state. The probability of exceeding a given value of variability according to the method in Sec. 2.2 is shown for the substantial threshold $\sigma_{S I A}>0.2$ in Fig. 8 (the maps for the $\sigma_{S I A}>0.1$ are shown in Fig. S6 in the supplementary material). The presented value is twice the threshold used in the previous analyses, to assess the probability of encountering highly variable sea-ice states.

It is evident that the probability of encountering high SIC variability is different from month to month in different sectors of the Southern Ocean. This explains why it is difficult to find consistent trends when computing hemispheric values of SIE. For instance, the Ross Sea presents the highest chance of finding variable sea-ice state in March over the entire region, while in December this is more likely in the Weddell Sea and the Indian sector up to $90^{\circ} \mathrm{E}$. The regions where the extent of sea ice from the continent is narrower, such as Eastern Antarctica, tend to show less variability in the sea-ice state. In more accurate terms, the probability of exceeding a high value of the indicator in East Antarctica sea ice is lower with respect to the other regions, but the whole sea-ice covered region should be classified as MIZ, since the probability of exceeding the 0.1 threshold is above $80 \%$ in every month (supplementary Fig. S6). This region is therefore one of the most interesting to capture the seasonal processes at the air-sea ice-ocean interface, because the MIZ remains confined within the same latitudinal band throughout the year.

In general, there are lower chances of exceeding the threshold value both in the outer edge and in the internal pack ice. This feature is caused by two different processes. At higher latitudes (mostly in autumn and winter), it is less likely to find variable conditions because the sea ice advances so far north only in a few years. February is an interesting month, because almost in every pixel in which sea ice has been observed in the satellite records there is a similarly low probability to exceed the threshold. This means that there are small chances of encountering brash ice but it is more likely that open drift conditions will be prevailing. At lower latitudes, on the other hand, the probability close to zero is because there are persistent pack ice or polynya conditions (the white regions between the coloured sectors and the Antarctic continent). They can be found in all months but March, which only shows the few regions of multi-year ice in the eastern Weddell Sea and the Ross Sea polynya. These are regions where consolidated conditions and sea-ice features that are more likely to be similar to the Arctic are found according to the satellite records.

June and July are instead the months of higher chances of encountering SIC variability away from the edge towards the interior of the Eastern Weddell Sea, and hence a sea-ice state that is more typical of the MIZ. In these regions, assuming pack ice conditions in numerical models and other conceptual considerations may lead to an underestimation of the air-sea exchanges. The SIC values may be generally close to $100 \%$, but the fluctuations around this value are large, which is indicative of a sea-ice state that is affected by boundary processes. 
Threshold $=0.2$
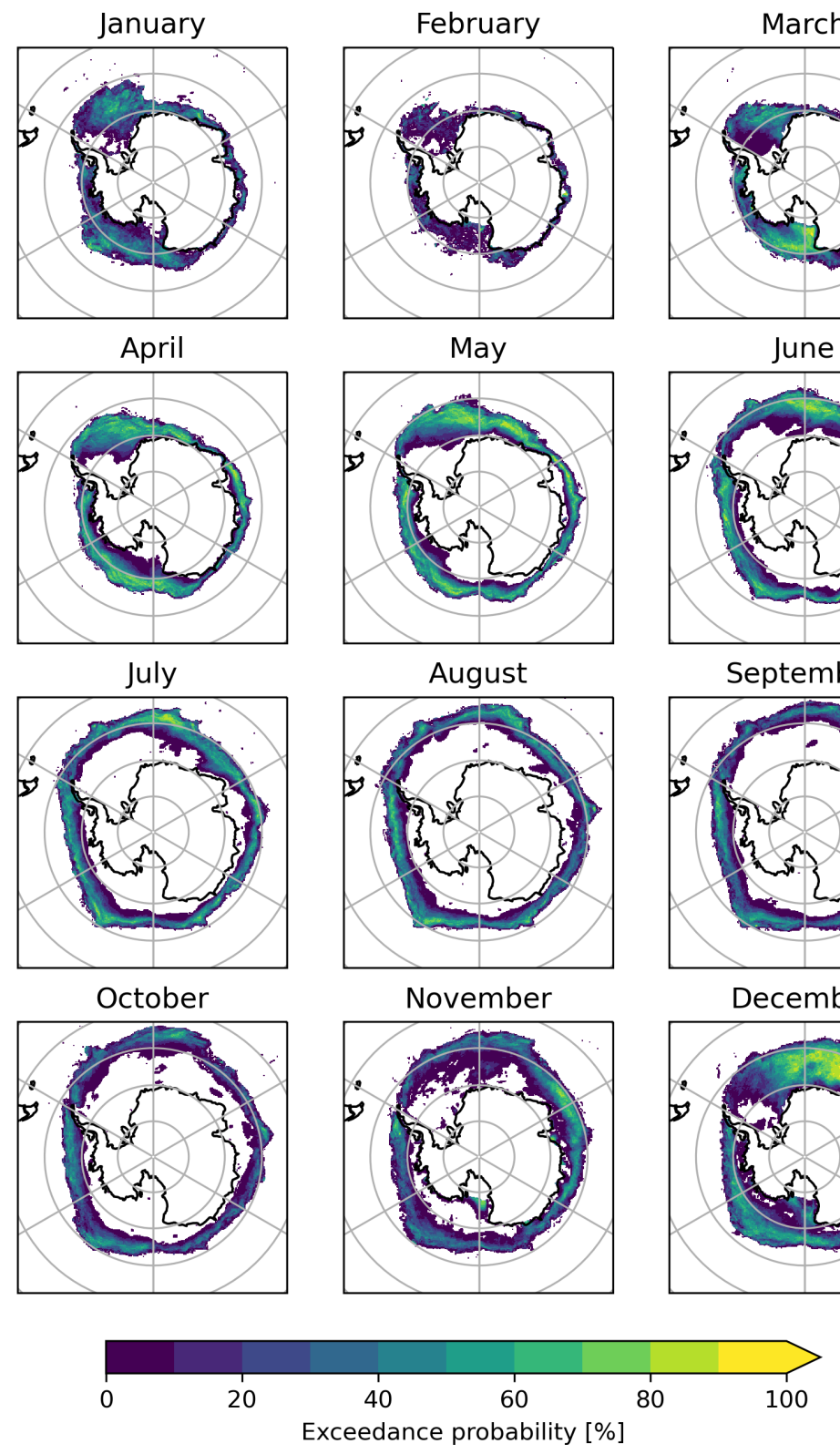
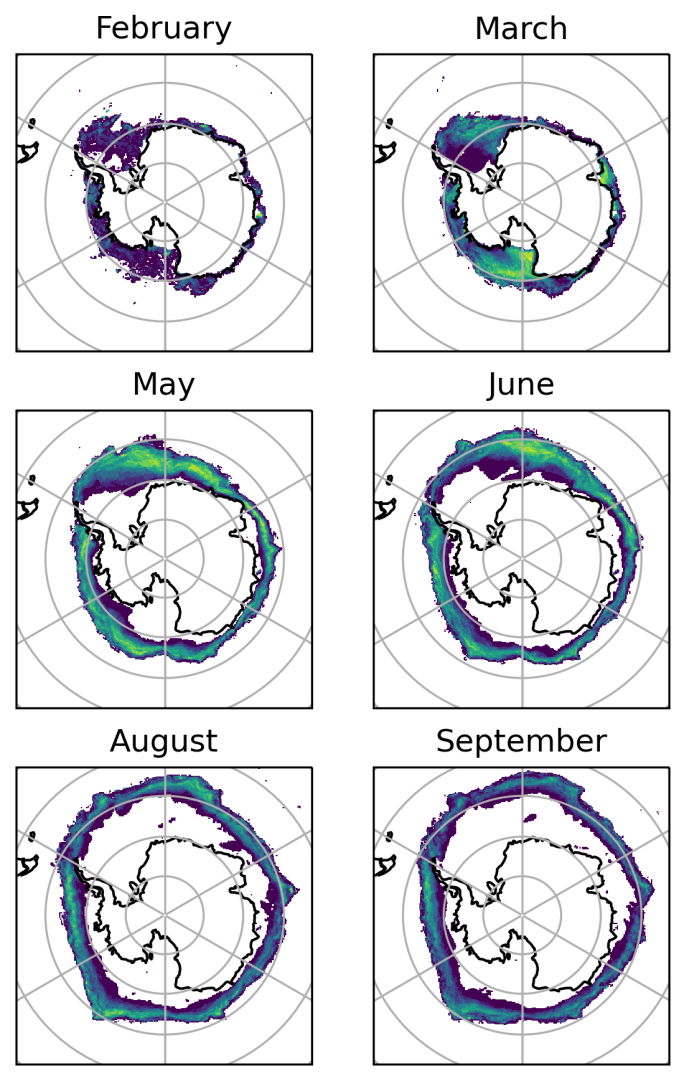

$$
\text { November }
$$
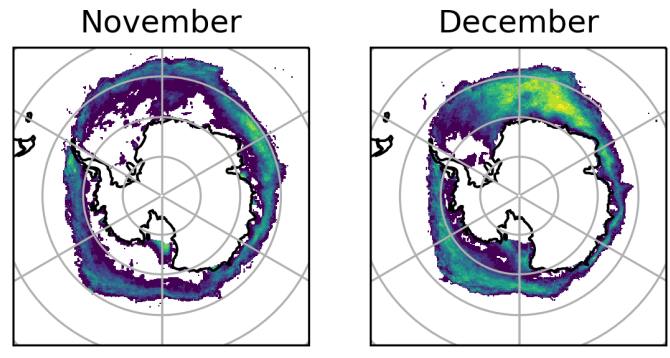

Figure 8. Monthly values of the exceedance probability for a threshold $\sigma_{S I A}=0.2$ from the NOAA/NSIDC CDR. 
https://doi.org/10.5194/tc-2021-307

Preprint. Discussion started: 27 October 2021

(c) Author(s) 2021. CC BY 4.0 License.

\section{(c) (i)}

\section{Discussion and conclusions}

The Antarctic marginal ice zone is characterised by highly variable sea-ice features in terms of texture, thickness and combination of ice types during its seasonal evolution. This work makes the assumption that such changes can be recorded in the variations of sea-ice concentration (SIC) measured through passive microwave sensors from space. This releases the constraints of defining the marginal ice zone through absolute, and subjective, concentration contours allowing to identify MIZ features in the whole ice-covered region. The conventional method uses a concentration threshold method to identify regions of sea-ice cover between 15 and 80\%. Due to the seasonal advancement and retreat of sea ice, the use of SIC monthly means allow to record some variability, which is then reflected in the overall count of pixels that can be attributed to be part of the MIZ (Strong and Rigor, 2013; Stroeve et al., 2016; Rolph et al., 2020). This work aims at reviewing the way we consider the Antarctic MIZ, shifting the perspective from considerations based on the absolute concentration to the relative variation. This is seen as one way to overcome the difficulties of detecting a clear relationship between concentration and ice type in the Southern Ocean, as proposed by Alberello et al. (2019) and Vichi et al. (2019).

Absolute SIC thresholds do not tell the whole story of the MIZ seasonal cycle, and especially they do not reflect a direct measure of variability, which is the ultimate feature of the MIZ. The proposed method allows to identify regions of higher variability and to quantify the climatological relative intensity. It gives a quantitative measure of the probability to exceed a given level of variation in SIC, which is obtained by computing an indicator: the standard deviation of the daily anomaly with respect to a monthly climatology. This indicator can be translated into maps of exceedance probability, hence giving a quantitative description of the likelihood of finding MIZ characteristics, beyond a more conventional fixed classification mask.

The method does not require subjective ranges, because the separation between pixels of low and high variability is obtained through a distributional analysis of the indicator values, which ultimately reveals a bimodal pattern. A threshold is nevertheless necessary, which is however derived from a distribution that distinguish regions of low variability, which are more typical of the inner pack regions, from the more variable MIZ regions. This implies that MIZ conditions can also be found, in agreement with the observed penetration of waves deep into the pack ice (Kohout et al., 2014, 2015; Stopa et al., 2018; Massom et al., 2018; Vichi et al., 2019; Kohout et al., 2020). The absolute probability value of exceeding a given threshold of variability depends on the chosen value of the indicator, but it does not modify the relative pattern between the regions.

One main aspect of this methodology is the use of daily SIC anomalies computed against the climatological monthly mean. This is based on the evidence that Antarctic sea ice has a clear seasonal pattern (Eayrs et al., 2019) but high variability from year to year and uncertain trends in different regions (Matear et al., 2015; Yuan et al., 2017; Parkinson, 2019). The use of this anomaly not only allows to capture changes affected by interannual variations (which would indeed be captured more adequately by using the anomaly with respect to the daily or weekly climatology) but also, and more specifically, the seasonal advance and retreat (which would disappear using the daily/weekly climatology) and the intra-monthly variability (pixels that show some change around the monthly climatology). All these criteria are typical of the marginal ice zone, and as demonstrated in this analysis, they are observed far into the region traditionally considered the realm of the pack ice. 
https://doi.org/10.5194/tc-2021-307

Preprint. Discussion started: 27 October 2021

(c) Author(s) 2021. CC BY 4.0 License.

(c) (i)

The presented results have shown that this indicator is independent of the algorithm and sensors, and less sensitive to the uncertainties of the brightness temperature retrieval (the standard 15\% threshold). As long as each product is consistent and not affected by intrinsic biases, the proposed analysis will map relative differences between ice types, even if the specific ice type cannot be classified. The use of a subjective SIC threshold for the MIZ definition leads to a misestimation of the sea-ice area that can be affected by variable conditions and different ice types in the various seasons. There is no apparent incongruence in the mismatch between different estimates of the MIZ extent. In terms of the seasonal climatology, the MIZ area obtained through the use of a fixed threshold is underestimated in winter, and far below the summer area. The estimated MIZ area using the indicator is instead much extended in summer. This may seem paradoxical, because the region classified as MIZ cannot be larger than the sea-ice extent. This is however an artefact of the use of climatological means and the $15 \%$ baseline, which skews the distribution towards the low values, disregarding the natural large variability of Antarctic sea ice and the diversity of ice types. The summer sea-ice extent based on concentration threshold is therefore underestimated. It is thus not surprising that identification of the ice edge is not carried out during summertime, because of the fragmentation of the ice surface.

These results have several applications. They introduce a broader perspective for assessing the predictability of ice conditions for forecasting, operational activities and also as a diagnostic to evaluate climate model capabilities to simulate the adequate conditions for ecosystem and biogeochemistry studies (Williams et al., 2014; Meynecke et al., 2020). Due to its construction, the method should be mostly applied in climatological or medium to long-term investigations of ice variability. It may also be used in an operational context, for instance comparing each daily anomaly against the long term distribution of anomalies in a particular region. This has not however been verified in this analysis and would deserve dedicated work. From an operational view point, these maps can be used to plan scientific and logistical activities in seasonally ice-covered Southern Ocean waters. This method should not be used to measure the extent of pack ice conditions, because multi-year ice is not counted due to the high-persistence and reduced inter-annual variability. The MIZ area could however be removed from the SIC-based seaice extent, to obtain an adjusted estimate that takes into account the regions of high variability. Finally, the possibility to see patterns of intensity within the region classified as MIZ, would allow to identify further linkages with the atmospheric boundary layer, as for instance looking for associations between regions of high synoptic variability and corresponding changes in the character of Antarctic sea ice.

Code and data availability. The EUMETSAT OSI-450 CDR product is freely available at https://doi.org/10.15770/EUM_SAF_OSI_0008 and the NOAA/NSIDC Climate Data Record of Passive Microwave Sea Ice Concentration, Version 3 can be downloaded from https://doi.org/10.7265/N59P2ZTG. The code used to produce the figures is available at https://github.com/mvichi/antarcticMIZ.git and the post-processed data used in the analysis will be made available through the ZivaHub repository at the University of Cape Town. 
https://doi.org/10.5194/tc-2021-307

Preprint. Discussion started: 27 October 2021

(C) Author(s) 2021. CC BY 4.0 License.

(c) (i)

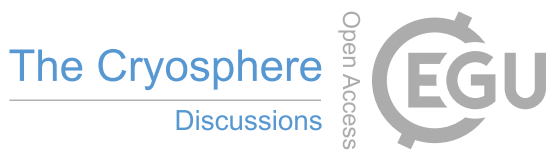

Competing interests. The author declares no competing interests.

Acknowledgements. This work has emerged from a collaboration between multiple projects. It has been supported by the National Research Foundation of South Africa (South African National Antarctic Programme and Earth System Science Research Program), the whalesandclimate.org project and the EU H2020 project CRiceS. 
https://doi.org/10.5194/tc-2021-307

Preprint. Discussion started: 27 October 2021

(c) Author(s) 2021. CC BY 4.0 License.

(c) (i)

\section{References}

Alberello, A., Onorato, M., Bennetts, L., Vichi, M., Eayrs, C., MacHutchon, K., and Toffoli, A.: Brief Communication: Pancake Ice Floe Size Distribution during the Winter Expansion of the Antarctic Marginal Ice Zone, The Cryosphere, 13, 41-48, https://doi.org/10.5194/tc13-41-2019, 2019.

Andreas, E. L., Lange, M. A., Ackley, S. F., and Wadhams, P.: Roughness of Weddell Sea Ice and Estimates of the Air-Ice Drag Coefficient, Journal of Geophysical Research: Oceans, 98, 12 439-12452, 1993.

Bigdeli, A., Hara, T., Loose, B., and Nguyen, A. T.: Wave Attenuation and Gas Exchange Velocity in Marginal Sea Ice Zone, Journal of Geophysical Research: Oceans, 123, 2293-2304, https://doi.org/10.1002/2017JC013380, 2018.

Castellani, G., Losch, M., Ungermann, M., and Gerdes, R.: Sea-Ice Drag as a Function of Deformation and Ice Cover: Effects on Simulated Sea Ice and Ocean Circulation in the Arctic, Ocean Modelling, 128, 48-66, https://doi.org/10.1016/j.ocemod.2018.06.002, 2018.

Comiso, J. C. and Zwally, H. J.: Concentration Gradients and Growth/Decay Characteristics of the Seasonal Sea Ice Cover, Journal of Geophysical Research: Oceans, 89, 8081-8103, https://doi.org/10.1029/JC089iC05p08081, 1984.

Eayrs, C., Holland, D., Francis, D., Wagner, T., Kumar, R., and Li, X.: Understanding the Seasonal Cycle of Antarctic Sea Ice Extent in the Context of Longer-Term Variability, Reviews of Geophysics, 57, 1037-1064, https://doi.org/10.1029/2018RG000631, 2019.

Gupta, M., Follows, M. J., and Lauderdale, J. M.: The Effect of Antarctic Sea Ice on Southern Ocean Carbon Outgassing: Capping Versus Light Attenuation, Global Biogeochemical Cycles, 34, e2019GB006 489, https://doi.org/10.1029/2019GB006489, 2020.

Haas, C.: Sea Ice Thickness Distribution, in: Sea Ice, chap. 2, pp. 42-64, John Wiley \& Sons, Ltd, https://doi.org/10.1002/9781118778371.ch2, 2017.

Haumann, F. A., Moorman, R., Riser, S. C., Smedsrud, L. H., Maksym, T., Wong, A. P. S., Wilson, E. A., Drucker, R., Talley, L. D., Johnson, K. S., Key, R. M., and Sarmiento, J. L.: Supercooled Southern Ocean Waters, Geophysical Research Letters, 47, e2020GL090 242, https://doi.org/10.1029/2020GL090242, 2020.

Kohout, A. L., Williams, M. J. M., Dean, S. M., and Meylan, M. H.: Storm-Induced Sea-Ice Breakup and the Implications for Ice Extent, Nature, 509, 604-607, https://doi.org/10.1038/nature13262, 2014.

Kohout, A. L., Penrose, B., Penrose, S., and Williams, M. J.: A Device for Measuring Wave-Induced Motion of Ice Floes in the Antarctic Marginal Ice Zone, Annals of Glaciology, 56, 415-424, 2015.

Kohout, A. L., Smith, M., Roach, L. A., Williams, G., Montiel, F., and Williams, M. J. M.: Observations of Exponential Wave Attenuation in Antarctic Sea Ice during the PIPERS Campaign, Annals of Glaciology, 61, 196-209, https://doi.org/10.1017/aog.2020.36, 2020.

Lavergne, T., Sørensen, A. M., Kern, S., Tonboe, R., Notz, D., Aaboe, S., Bell, L., Dybkjær, G., Eastwood, S., Gabarro, C., Heygster, G., Killie, M. A., Brandt Kreiner, M., Lavelle, J., Saldo, R., Sandven, S., and Pedersen, L. T.: Version 2 of the EUMETSAT OSI SAF and ESA CCI Sea-Ice Concentration Climate Data Records, The Cryosphere, 13, 49-78, https://doi.org/10.5194/tc-13-49-2019, 2019.

Maksym, T.: Arctic and Antarctic Sea Ice Change: Contrasts, Commonalities, and Causes, Annu. Rev. Mar. Sci., 11, 187-213, https://doi.org/10.1146/annurev-marine-010816-060610, 2019.

Martinson, D. G. and Iannuzzi, R. A.: Antarctic Ocean-Ice Interaction: Implications from Ocean Bulk Property Distributions in the Weddell Gyre, in: Antarctic Sea Ice: Physical Processes, Interactions and Variability, pp. 243-271, American Geophysical Union (AGU), https://doi.org/10.1029/AR074p0243, 1998.

370 Martinson, D. G. and Wamser, C.: Ice Drift and Momentum Exchange in Winter Antarctic Pack Ice, Journal of Geophysical Research: Oceans, 95, 1741-1755, https://doi.org/10.1029/JC095iC02p01741, 1990. 
https://doi.org/10.5194/tc-2021-307

Preprint. Discussion started: 27 October 2021

(c) Author(s) 2021. CC BY 4.0 License.

(c) (i)

Massom, R. A., Scambos, T. A., Bennetts, L. G., Reid, P., Squire, V. A., and Stammerjohn, S. E.: Antarctic Ice Shelf Disintegration Triggered by Sea Ice Loss and Ocean Swell, Nature, 558, 383, https://doi.org/10.1038/s41586-018-0212-1, 2018.

Matear, R. J., O’Kane, T. J., Risbey, J. S., and Chamberlain, M.: Sources of Heterogeneous Variability and Trends in Antarctic Sea-Ice, Nature Communications, 6, 8656, https://doi.org/10.1038/ncomms9656, 2015.

Matsumura, Y. and Ohshima, K. I.: Lagrangian Modelling of Frazil Ice in the Ocean, Annals of Glaciology, 56, 373-382, https://doi.org/10.3189/2015AoG69A657, 2015.

Meier, W. N. and Stroeve, J.: Comparison of Sea-Ice Extent and Ice-Edge Location Estimates from Passive Microwave and EnhancedResolution Scatterometer Data, Annals of Glaciology, 48, 65-70, https://doi.org/10.3189/172756408784700743, 2008/ed.

Meier, W. N., Fetterer, F., Savoie, M. H., Mallory, M., Duerr, R., and Stroeve, J. C.: NOAA/NSIDC Climate Data Record of Passive Microwave Sea Ice Concentration, Version 3, https://doi.org/10.7265/N59P2ZTG, 2017.

Meynecke, J.-O., Seyboth, E., Bie, J. D., Barraqueta, J.-L. M., Chama, A., Dey, S. P., Lee, S. B., Tulloch, V., Vichi, M., Findlay, K., Roychoudhury, A. N., and Mackey, B.: Responses of Humpback Whales to a Changing Climate in the Southern Hemisphere: Priorities for Research Efforts, Marine Ecology, n/a, e12 616, https://doi.org/10.1111/maec.12616, 2020.

Parkinson, C. L.: A 40-y Record Reveals Gradual Antarctic Sea Ice Increases Followed by Decreases at Rates Far Exceeding the Rates Seen in the Arctic, PNAS, 116, 14 414-14 423, https://doi.org/10.1073/pnas.1906556116, 2019.

Paul, F., Mielke, T., Schwarz, C., Schröder, J., Rampai, T., Skatulla, S., Audh, R. R., Hepworth, E., Vichi, M., and Lupascu, D. C.: Frazil Ice in the Antarctic Marginal Ice Zone, Journal of Marine Science and Engineering, 9, 647, https://doi.org/10.3390/jmse9060647, 2021.

Peng, G., Meier, W. N., Scott, D. J., and Savoie, M. H.: A Long-Term and Reproducible Passive Microwave Sea Ice Concentration Data Record for Climate Studies and Monitoring, Earth System Science Data, 5, 311-318, https://doi.org/10.5194/essd-5-311-2013, 2013.

Petrich, C. and Eicken, H.: Overview of Sea Ice Growth and Properties, in: Sea Ice, chap. 1, pp. 1-41, John Wiley \& Sons, Ltd, https://doi.org/10.1002/9781118778371.ch1, 2017.

Rolph, R. J., Feltham, D. L., and Schröder, D.: Changes of the Arctic Marginal Ice Zone during the Satellite Era, The Cryosphere, 14, 1971-1984, https://doi.org/10.5194/tc-14-1971-2020, 2020.

Squire, V. A.: Ocean Wave Interactions with Sea Ice: A Reappraisal, Annu. Rev. Fluid Mech., 52, 37-60, https://doi.org/10.1146/annurevfluid-010719-060301, 2020.

Steele, M., Morison, J. H., and Untersteiner, N.: The Partition of Air-Ice-Ocean Momentum Exchange as a Function of Ice Concentration, Floe Size, and Draft, Journal of Geophysical Research: Oceans, 94, 12 739-12 750, https://doi.org/10.1029/JC094iC09p12739, 1989.

Stopa, J. E., Ardhuin, F., Thomson, J., Smith, M. M., Kohout, A., Doble, M., and Wadhams, P.: Wave Attenuation Through an Arctic Marginal Ice Zone on 12 October 2015: 1. Measurement of Wave Spectra and Ice Features From Sentinel 1A, Journal of Geophysical Research: Oceans, 123, 3619-3634, https://doi.org/10.1029/2018JC013791, 2018.

Stroeve, J. C., Jenouvrier, S., Campbell, G. G., Barbraud, C., and Delord, K.: Mapping and Assessing Variability in the Antarctic Marginal Ice Zone, Pack Ice and Coastal Polynyas in Two Sea Ice Algorithms with Implications on Breeding Success of Snow Petrels, The Cryosphere, 10, 1823-1843, https://doi.org/10.5194/tc-10-1823-2016, 2016.

Strong, C.: Atmospheric Influence on Arctic Marginal Ice Zone Position and Width in the Atlantic Sector, February-April 1979-2010, Clim Dyn, 39, 3091-3102, https://doi.org/10.1007/s00382-012-1356-6, 2012.

Strong, C. and Rigor, I. G.: Arctic Marginal Ice Zone Trending Wider in Summer and Narrower in Winter, Geophysical Research Letters, 40, 4864-4868, https://doi.org/10.1002/grl.50928, 2013. 
https://doi.org/10.5194/tc-2021-307

Preprint. Discussion started: 27 October 2021

(c) Author(s) 2021. CC BY 4.0 License.

(c) (i)

Strong, C., Foster, D., Cherkaev, E., Eisenman, I., and Golden, K. M.: On the Definition of Marginal Ice Zone Width, Journal of Atmospheric and Oceanic Technology, 34, 1565-1584, https://doi.org/10.1175/JTECH-D-16-0171.1, 2017.

Sutherland, P. and Dumont, D.: Marginal Ice Zone Thickness and Extent Due to Wave Radiation Stress, Journal of Physical Oceanography, 48, 1885-1901, https://doi.org/10.1175/JPO-D-17-0167.1, 2018.

Turner, J., Phillips, T., Marshall, G. J., Hosking, J. S., Pope, J. O., Bracegirdle, T. J., and Deb, P.: Unprecedented Springtime Retreat of Antarctic Sea Ice in 2016, Geophysical Research Letters, 44, 6868-6875, https://doi.org/10.1002/2017GL073656, 2017.

415 Vichi, M., Eayrs, C., Alberello, A., Bekker, A., Bennetts, L., Holland, D., de Jong, E., Joubert, W., MacHutchon, K., Messori, G., Mojica, J. F., Onorato, M., Saunders, C., Skatulla, S., and Toffoli, A.: Effects of an Explosive Polar Cyclone Crossing the Antarctic Marginal Ice Zone, Geophysical Research Letters, p. 2019GL082457, https://doi.org/10.1029/2019GL082457, 2019.

Wadhams, P.: Ice in the Ocean, CRC Press, Boca Raton, New York, Oxon, 2000.

Weeks, W. F.: On Sea Ice, University of Alaska Press, Fairbanks, 2010.

Weeks, W. F. and Ackley, S. F.: The Growth, Structure, and Properties of Sea Ice, in: The Geophysics of Sea Ice, edited by Untersteiner, N., NATO ASI Series, pp. 9-164, Springer US, Boston, MA, https://doi.org/10.1007/978-1-4899-5352-0_2, 1986.

Williams, R., Kelly, N., Boebel, O., Friedlaender, A. S., Herr, H., Kock, K.-H., Lehnert, L. S., Maksym, T., Roberts, J., Scheidat, M., Siebert, U., and Brierley, A. S.: Counting Whales in a Challenging, Changing Environment, Scientific Reports, 4, 4170, https://doi.org/10.1038/srep04170, 2014.

Williams, T. D., Bennetts, L. G., Squire, V. A., Dumont, D., and Bertino, L.: Wave-Ice Interactions in the Marginal Ice Zone. Part 2: Numerical Implementation and Sensitivity Studies along 1D Transects of the Ocean Surface, Ocean Modelling, 71, 92-101, https://doi.org/10.1016/j.ocemod.2013.05.011, 2013.

Worby, A. P. and Allison, I.: Ocean-Atmosphere Energy Exchange over Thin, Variable Concentration Antarctic Pack Ice, Annals of Glaciology, 15, 184-190, https://doi.org/10.3189/1991AoG15-1-184-190, 1991.

Worby, A. P. and Comiso, J. C.: Studies of the Antarctic Sea Ice Edge and Ice Extent from Satellite and Ship Observations, Remote Sensing of Environment, 92, 98-111, https://doi.org/10.1016/j.rse.2004.05.007, 2004.

Worby, A. P., Jeffries, M. O., Weeks, W. F., Morris, K., and Jaña, R.: The Thickness Distribution of Sea Ice and Snow Cover during Late Winter in the Bellingshausen and Amundsen Seas, Antarctica, Journal of Geophysical Research: Oceans, 101, 28 441-28455, https://doi.org/10.1029/96JC02737, 1996.

435 Yuan, N., Ding, M., Ludescher, J., and Bunde, A.: Increase of the Antarctic Sea Ice Extent Is Highly Significant Only in the Ross Sea, Scientific Reports, 7, 41 096, https://doi.org/10.1038/srep41096, 2017. 